\title{
HYGROMECHANICAL STRAINS DURING THE DRYING OF Eucalyptus nitens BOARDS
}

\author{
N. Pérez-Peña ${ }^{1, \AA}$, A. Cloutier ${ }^{2}$, F. Segovia ${ }^{2}$, C. Salinas-Lira ${ }^{3}$, \\ V. Sepúlveda-Villarroel ${ }^{1}$, L. Salvo-Sepúlveda ${ }^{1}$, D.M. Elustondo ${ }^{4}$, \\ R. A. Ananías ${ }^{1}$
}

\begin{abstract}
Collapse and drying stresses are currently induced during the drying of Eucalyptus nitens in solid wood products. The purpose of this study was to investigate these drying stresses by measuring hygromechanical strains during the drying of Eucalyptus nitens boards.

Small samples of Eucalyptus nitens wood were oriented in the radial and tangential directions and tested to determine the hygromechanical strains during the drying process. This experimental work consisted of cantilevered bending tests conducted under variable relative humidity conditions. Tests were performed in a conditioning chamber at $30{ }^{\circ} \mathrm{C}$ with an equilibrium moisture content ranging from 22 to $12 \%$ under four levels of stress: $0,10,20$ and $30 \%$ of the rupture load. The strains were determined using strain gauges, and the total deflection was measured with a linear variable differential transformer.

The results show that in hygromechanical strains during the drying of Eucalyptus nitens, both the surface deformation and mechano-sorption strain were found to be proportional to the applied stress and reached their maximum values in the tangential direction. The total deflection increased $0,18 \mathrm{~mm} / \mathrm{mm}$ with a surface deformation of $0,20 \mathrm{~mm} / \mathrm{mm}$, and the mechano-sorptive strain provides a greater contribution with a value of $0,11 \mathrm{~mm} / \mathrm{mm}$, thus corresponding to $59 \%$ of the total deformation. In attempts to improve the drying schedules of Eucalyptus nitens to develop solid wood products, mechano-sorptive behavior may be applied to relieve collapse and drying stress.
\end{abstract}

Keywords: Deflection, deformation, drying stresses, mechano-sorption, wood drying.

\section{INTRODUCTION}

The complex mechanical behavior of wood should be considered to understand wood behavior during the drying and desorption processes. It has been demonstrated that the mechanical behavior during wood drying is strongly dependent on temperature, relative humidity, time and applied load, among others factors (Moutee et al. 2010). During the drying process, wood experiences differential shrinkage between the surface and the core, which induces the development of mechanical stresses

\footnotetext{
${ }^{1}$ Research Group on Wood Drying Technology \& Thermal Treatments, Department of Wood Engineering, University of Bio-Bio, Concepción, Chile.

${ }^{2}$ Département des Sciences du Bois et de la Forêt, Université Laval, Québec, Canada.

${ }^{3}$ Research Group on Wood Drying Technology \& Thermal Treatments, Department of Mechanical Engineering, University of

Bio-Bio, Concepción, Chile.

${ }^{4}$ Division of Wood Science and Technology, Lulea Technological University, Skelleftea, Sweden.

"Corresponding author: ndperez@alumnos.ubiobio.cl
}

Received: 05.06.2015 Accepted: 14.12.2015 
across the structure (Pang 2002, Clair 2012). Shrinkage begins to develop on the wood surface when the moisture content (MC) decreases below the fiber saturation point (FSP), and the shrinkage is restrained by the internal region that remains above the FSP. Thus, the external surfaces generate tension in the direction of the undeveloped shrinkage, placing the internal regions under compression and generating tension in the opposite direction (Salinas et al. 2015).

The stress level caused by drying depends on several factors, such as the drying temperature, drying time, wood species, sawing pattern, board thickness, ring width, growth rate (Keey et al. 2000, Pang 2000). These stress-induced deformations are recognized as an important cause of wood instability and decreased quality in the final wood product. It is well known that the total deformation that occurs during drying involves free shrinkage and mechano-sorptive, elastic instantaneous and visco-elastic creep components (Kang et al. 2004).

When the MC is below the FPS, wood will shrink, and wood shrinkage is greater in the tangential direction than the longitudinal direction. When wood is subjected to changes in the MC under a load, greater deformations are observed than when wood is under conditions of constant humidity (Mårtensson 1994).

Mechano-sorption (MS) strain is a phenomenon that occurs when wood is subjected to stresses and changes in the MC (Armstrong and Kingston 1962). This strain is considered to be greater than the strain that occurs under constant MC conditions (Mårtensson 1994). MS strain is also temperature dependent and is greater when the wood is under load (Erikson 1994). Lazarescu et al. (2009) indicate that MS strain can be interpreted as accelerated creep due to the variation in the equilibrium moisture content (EMC). Additionally, they note that MS strain is the result of the transient redistribution of stresses associated with the variation in the moisture content, which causes the rupture of hydrogen bonds. In wood drying, MS deformation is responsible for the mitigation of drying stresses that otherwise might result in surface checking and cause severe losses (Langrish 2013). Additionally, Fu et al. (2013) show that mechano-sorption is dependent on the radial position of the log. Hassani et al. (2015) indicate that MS strain is greater in the perpendicular direction than in the parallel direction.

When wood samples are subjected to drying (desorption), the strain rate increases. Experimentally, wood has been observed to exhibit greater deformation under variable conditions (temperature and relative humidity) than under constant conditions.

During the drying at low temperature of Eucalyptus nitens in solid wood products, collapse and drying stresses are induced. During drying of the E. nitens boards, it was preliminarily observed that internal strain developed and reached its maximum level at approximately $1 / 4$ of the treatment duration (Sepúlveda et al. 2015).

The objective of this study was to determine the mechanical deformations and total deflection produced in E. nitens wood during the drying process. This paper presents the results of laboratory experiments involving samples arranged in the tangential and radial directions in a cantilevered bending test during the drying process, with variable relative humidity conditions and under different load levels.

\section{MATERIALS AND METHODS}

The material consisted of 18 samples of Eucalyptus nitens sapwood (9 radial and 9 tangential) collected from three 12 year-old trees, without grain deviation.

These pieces were then stored in a conditioning chamber at $30^{\circ} \mathrm{C}$ and $93 \%$ of relative humidity with a mean value of $22 \%$ of EMC and used in the preparation of samples oriented parallel to the two perpendicular orthotropic axes (radial and tangential). There were 12 samples for each direction, and the final dimensions were $110 \mathrm{~mm}$ (length) $\times 25 \mathrm{~mm}$ (width) $\times 7 \mathrm{~mm}$ (thickness). 


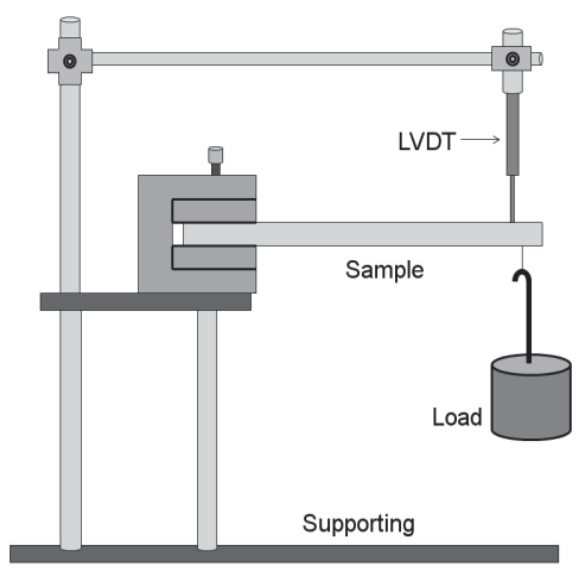

Figure 1. Schema of experimental cantilever test.

The experimental work consisted of a cantilever bending test performed during the drying process (Moutee et al. 2005, Segovia et al. 2013). During the test, one end of each sample was firmly secured to a metal support, and a load was applied to the sample's free end (Figure 1). The tests were performed in a conditioning chamber at a constant temperature of $30{ }^{\circ} \mathrm{C}$ with variable relative humidity $(\mathrm{RH})$ conditions and an EMC of 22 to 12\%. Four load levels were considered for the tests: 0, 10, 20 and 30\% of the rupture load. The experimental conditions for each test are shown in Table 1.

Table 1. Experimental data.

\begin{tabular}{|c|c|c|c|c|c|c|c|c|}
\hline \multirow[b]{2}{*}{ Direction } & \multirow{2}{*}{$\begin{array}{c}\text { Temperature } \\
\left({ }^{\circ} \mathrm{C}\right)\end{array}$} & \multirow{2}{*}{$\begin{array}{c}\text { EMC variation } \\
(\%)\end{array}$} & \multirow{2}{*}{$\begin{array}{l}\text { Rupture load } \\
\text { (g) }\end{array}$} & \multicolumn{4}{|c|}{ Level load (g) } & \multirow{2}{*}{$\begin{array}{c}\mathrm{N} \\
\text { samples }\end{array}$} \\
\hline & & & & $0 \%$ & $10 \%$ & $20 \%$ & $30 \%$ & \\
\hline Radial & 30 & $\begin{array}{l}22-17 \\
17-12 \\
\end{array}$ & 4898 & 0 & 490 & 980 & 1470 & 12 \\
\hline Tangential & 30 & $\begin{array}{l}22-17 \\
17-12\end{array}$ & 2973 & 0 & 297 & 594 & 891 & 12 \\
\hline
\end{tabular}

Note: the rupture load value is the average of 10 repetitions.

The rupture load value was obtained in samples previously conditioned to $22 \%$ of the EMC, using the same experimental setup by manually and progressively increasing small loads at the free ends of the samples until the rupture point was reached. For each direction, the rupture load value represents the average of 10 repetitions.

The surface deformation measurement of the samples was performed using strain gauges (calibrated according to the producer's conditions) bonded to the upper face within $25 \mathrm{~mm}$ of the assurance area. At the same time, the maximum deflection was determined using linear variable differential transformer (LVDT) displacement sensors located $15 \mathrm{~mm}$ from the free ends of the samples. The load application point was located $5 \mathrm{~mm}$ away from the LVDT and $10 \mathrm{~mm}$ from the free ends of the samples (Figure 2). 


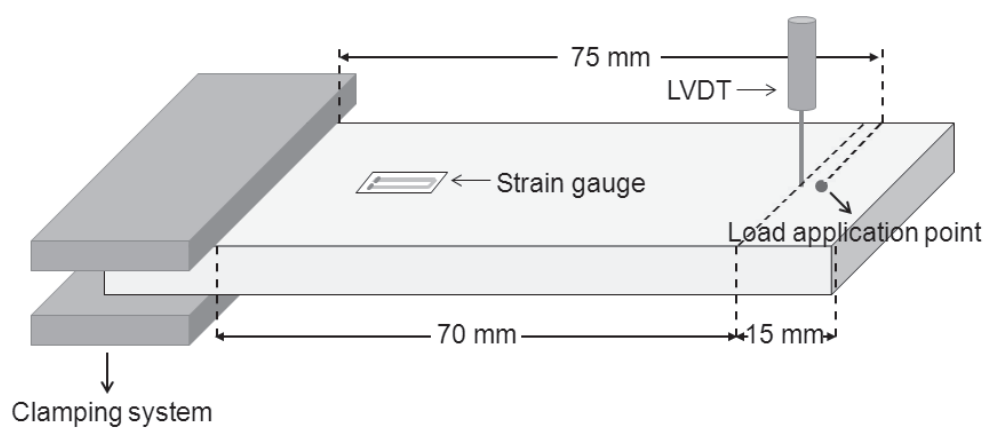

Figure 2. Schema of location of LVDT load application point.

The strain gauges and the LVDT were connected to a data acquisition system (Stress Analysis Data System 5000), which allowed the monitoring of information in real time and recorded the data every second.

The shrinkage deformation was measured in the free load sample, and the instantaneous or elastic deformation was measured after the load application. The MS strain was obtained by subtracting the instantaneous and shrinkage deformation of the total deformations.

To determine the EMCs, three control samples were placed in the conditioning chamber, thus allowing the $\mathrm{MC}$ variation to be monitored over time. Samples were weighed daily using a balance with an accuracy of $0,001 \mathrm{~g}$. At the end of conditioning, the oven-dry weights of the samples were obtained and used to calculate the average moisture content of the samples over time.

A statistical analysis (Kruskall-Wallis test) was performed to evaluate the effect of the moisture content, load level and anatomical orientation on the MS strains.

\section{RESULTS AND DISCUSSION}

Figure 3 shows the evolution of the total deflection at $30^{\circ} \mathrm{C}$ undervariable RH conditions (Table 1 ) with applied loads equal to 10,20 and $30 \%$ of the rupture load for the two perpendicular directions. During the first 48 hours of loading, the total strain was observed. After the first change in RH from $93 \%$ to $83 \%$, the EMC changed from $22 \%$ to $17 \%$, demonstrating an increase in total strain. With the next RH change from $83 \%$ to $67 \%$, the EMC changed from $17 \%$ to $12 \%$, and the total strain increased again for the two directions. 


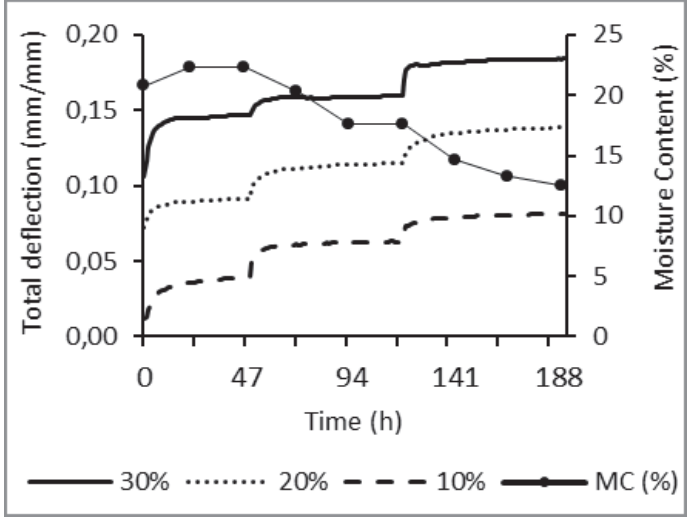

(a)

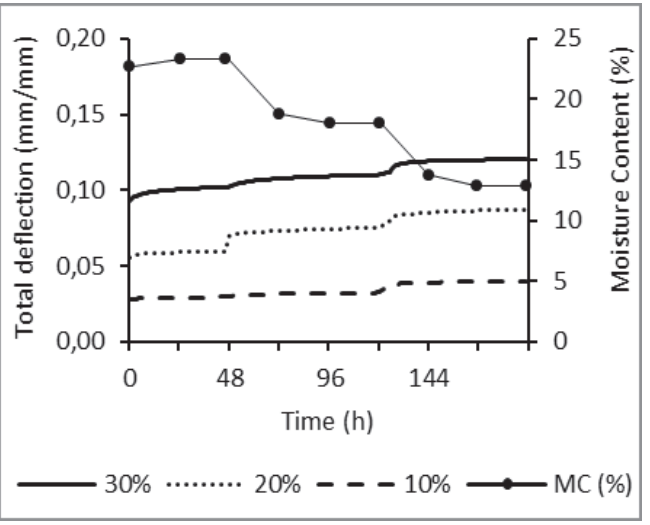

(b)

Figure 3. Total deflection during drying of Eucalyptus nitens boards.

(a) radial and (b) tangential.

The maximum strain was observed in samples oriented in the tangential direction, with an average value of $0,183 \mathrm{~mm} / \mathrm{mm}$; the radial samples were observed to reach $0,12 \mathrm{~mm} / \mathrm{mm}$ for the greatest load (30\% of the rupture load).

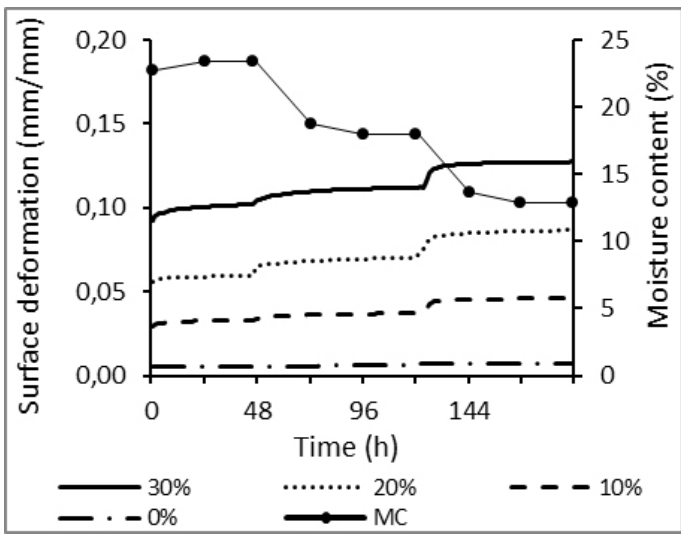

(a)

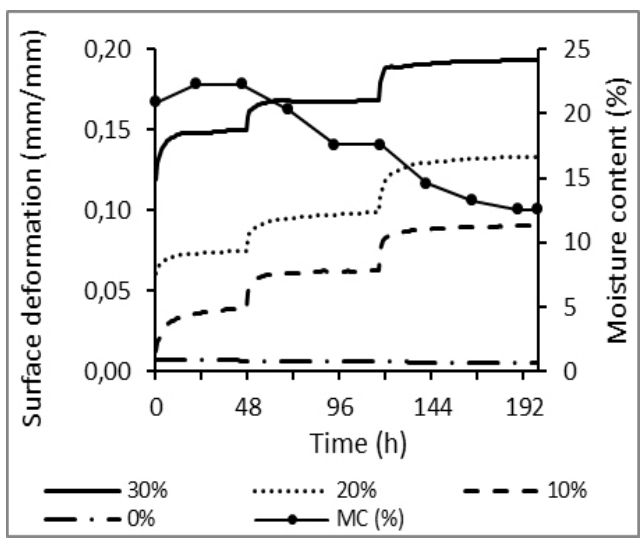

(b)

Figure 4. Surface deformation during drying of Eucalyptus nitens boards.

(a) radial and (b) tangential.

Figure 4 shows the results of surface deformation in relation to the variation of the wood MC for the four load levels and the two perpendicular directions. The curve at $0 \%$ of the rupture load corresponded to the deformation for free shrinkage. At $10 \%, 20 \%$ and $30 \%$ of the rupture load, instantaneous deformation occurred immediately upon loading and was proportional to the applied load (elastic behavior). After the first change in $\mathrm{RH}$, when the wood moisture content decreased from $22 \%$ to $17 \%$, the surface deformation increased rapidly, demonstrating the occurrence of MS deformation 
and coincides with the description of the phenomenon of mechano-sorptive creep that consists in an increase of creep deformation during any desorption (Hunt and Shelton 1988).

The surface deformation was found to be proportional to the applied load level and reached its maximum value in the tangential direction. These average values were 0,$19 ; 0,13$ and $0,09 \mathrm{~mm} / \mathrm{mm}$ for 30,20 and $10 \%$ of the rupture load, respectively. For the radial direction, the value of the surface deformation was 0,12 for $30 \%$ of the rupture load.

Additionally, it can be observed in Figures 3 and 4 that the curves show the same trend under load. Consequently, either of these two measurement techniques appears to be suitable for strain determination.

Table 2. Average deformations: instantaneous, free shrinkage and mechano-sorption (MS).

\begin{tabular}{|c|c|c|c|c|c|}
\hline Direction & $\begin{array}{l}\text { Load } \\
\text { level }\end{array}$ & $\begin{array}{c}\text { Total } \\
\text { deformation } \\
(\mathrm{mm} / \mathrm{mm})\end{array}$ & $\begin{array}{l}\text { Instantaneous } \\
\text { deformation } \\
(\mathrm{mm} / \mathrm{mm})\end{array}$ & $\begin{array}{l}\text { Shrinkage } \\
\text { deformation } \\
(\mathrm{mm} / \mathrm{mm})\end{array}$ & $\begin{array}{c}\text { MS } \\
\text { deformation } \\
(\mathrm{mm} / \mathrm{mm})\end{array}$ \\
\hline \multirow{3}{*}{ Radial } & $30 \%$ & $\begin{array}{c}0,1273 \\
(0,0010) \\
\end{array}$ & $\begin{array}{c}0,0507 \\
(1,3 \mathrm{E}-17) \\
\end{array}$ & \multirow{3}{*}{$\begin{array}{c}0,00517 \\
(7,9 \mathrm{E}-05)\end{array}$} & $\begin{array}{c}0,0714 \\
(0,00097) \\
\end{array}$ \\
\hline & $20 \%$ & $\begin{array}{c}0,0867 \\
(0,0011)\end{array}$ & $\begin{array}{c}0,0319 \\
(6,9 \mathrm{E}-18)\end{array}$ & & $\begin{array}{c}0,0548 \\
(0,00098)\end{array}$ \\
\hline & $10 \%$ & $\begin{array}{c}0,0461 \\
(0,0005) \\
\end{array}$ & $\begin{array}{c}0,0205 \\
(1,7 \mathrm{E}-18) \\
\end{array}$ & & $\begin{array}{c}0,0256 \\
(0,00046) \\
\end{array}$ \\
\hline \multirow{3}{*}{ Tangential } & $30 \%$ & $\begin{array}{c}0,1934 \\
(0,0018)\end{array}$ & $\begin{array}{c}0,0671 \\
(2,1 \mathrm{E}-17)\end{array}$ & \multirow{3}{*}{$\begin{array}{c}0,01144 \\
(7,8 \mathrm{E}-05)\end{array}$} & $\begin{array}{c}0,1148 \\
(0,0019)\end{array}$ \\
\hline & $20 \%$ & $\begin{array}{c}0,1335 \\
(0,0023)\end{array}$ & $\begin{array}{c}0,0436 \\
(6,1 \mathrm{E}-18)\end{array}$ & & $\begin{array}{c}0,0899 \\
(0,0024)\end{array}$ \\
\hline & $10 \%$ & $\begin{array}{c}0,0905 \\
(0,0021)\end{array}$ & $\begin{array}{c}0,0332 \\
(2,2 \mathrm{E}-18)\end{array}$ & & $\begin{array}{c}0,0573 \\
(0,0022)\end{array}$ \\
\hline
\end{tabular}

(Standard deviations)

Table 2 shows the instantaneous deformation, free shrinkage and MS deformation results for each perpendicular direction measured. The maximum value of the instantaneous deformation was 0,0671 in the tangential direction. This value is higher than the results obtained by Langrish (2013), reported a value of 0,0148 for cyclic drying from 45 to $55^{\circ}$.

Additionally, the MS strain is proportional to the load level and contributes significantly to the total deformation (Table 3). 
Table 3. Effect of load level on MS strain (test de Kruskal-Wallis).

\begin{tabular}{|c|c|c|c|c|c|c|c|}
\hline Variable & Load level (\%) & $\mathrm{N}$ & Mean & D.E. & Median & H & $\mathrm{p}$ \\
\hline MS strain & 30 & 384 & 0,034 & 0,002 & 0,0028 & 558,7929 & $<0,0001$ \\
\hline MS strain & 20 & 384 & 0,059 & 0,0024 & 0,0056 & & \\
\hline MS strain & 10 & 384 & 0,092 & 0,003 & 0,0079 & & \\
\hline
\end{tabular}

The perpendicular MS strains during the desorption of E. nitens boards depended significantly on the wood orientation (Table 4). Higher MS strain values developed in the tangential direction; in this anatomical orientation, the MS strain reached a maximum value of $0,11 \mathrm{~mm} / \mathrm{mm}$ for the highest load level, corresponding to $59 \%$ of the total deformation.

Table 4. Effect of anatomical direction on MS strain (test de Kruskal Wallis).

\begin{tabular}{|c|c|c|c|c|c|c|c|}
\hline Variable & Direction & $\mathrm{N}$ & Mean & D.E. & Median & $\mathrm{H}$ & $\mathrm{p}$ \\
\hline MS strain & Radial & 576 & 0,044 & 0,0020 & 0,0042 & 277,9064 & $<0,0001$ \\
\hline MS strain & Tangential & 576 & 0,079 & 0,0037 & 0,0071 & & \\
\hline
\end{tabular}

Additionally, the MS strain was higher when the MC decrease. As shown in Figure 5, this variation was significant.

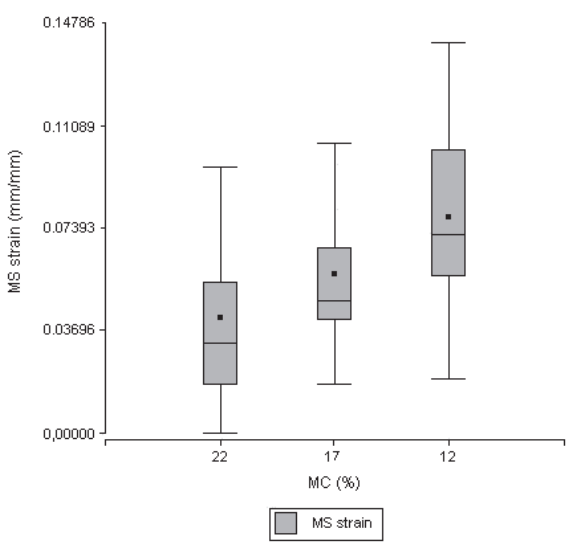

Figure 5. Effect of moisture content on MS strains.

These findings can be used as indicators of hygromechanical behavior for mitigation of collapse and drying stresses when processing quarter-sawn wood. Chen and Gu (2006) and Langrish (2013) show that the MS strain relaxes the drying stresses during conditioning. The drying of solid E. nitens wood is limited by its propensity to collapse (Ananías et al. 2014) and, according to Blakemore (2011); drying stresses mitigate the collapse during the drying of eucalypts. Perpendicular MS strains during the drying of E. nitens boards are dependent on the orientation of the wood, and higher values of MS strains are developed in the tangential direction. 


\section{CONCLUSIONS}

The significant contribution of MS strain to total deformation was confirmed.

In the tangential direction, the MS strain reached a maximum value of $0,11 \mathrm{~mm} / \mathrm{mm}$ for the higher load level, corresponding to $59 \%$ of the total deformation.

The surface deformation and total deflection were proportional to the applied stress in the two directions. Both reached their maximum values in the tangential direction, with values of $0,2 \mathrm{~mm} / \mathrm{mm}$ and $0,183 \mathrm{~mm} / \mathrm{mm}$, respectively.

Attempting to improve the drying schedules of Eucalyptus nitens for the development of solid wood products, mechano-sorptive behavior may be applied to relieve collapse and drying stresses.

Future work should include a model of the drying stresses to improve the drying of Eucalyptus nitens wood.

\section{ACKNOWLEDGEMENTS}

The authors appreciate the financial support of the National Commission of Scientific \& Technological Research (Conicyt) of Chile (Fondecyt No 1110500).

\section{REFERENCES}

Ananías, R.A.; Sepúlveda, V.; Pérez, N.; Leandro, L.; Salvo, L.; Salinas, C.; Cloutier, A.; Elustondo, D.M. 2014. Collapse of Eucalyptus nitens wood after drying depending on the radial location within the stem. Drying Technology 32(14):1699-1705.

Armstrong, L. D.; Kingston, R. S. T.1962. The effect of moisture content changes on the deformation of wood under stress. Australian Journal of Applied Science 13(4):257-276.

Blakemore, P. 2011. Internal checking during Eucalypts processing. Ch 12, in Delamination in wood, wood products and wood based composites, Ed. B. Bucur. Springer, N. York. 237-254.

Clair, B. 2012. Evidence that release of internal stress contributes to drying strains of wood. Holzforschung 66:349-353.

Chen, T.; Gu, L. 2006. Development of elastic strain and mechano-sorptive strain during conditioning of Eucalyptus camaldulensis lumber in batch kiln. Maderas. Ciencia y tecnología 8(1):4956. 
Erikson, R. 1994. The effect of drying temperature on the mechano-sorptive behavior of red oak lumber. Drying Technology 12(8):1943-1961.

Fu, Z; Cai, Y.; Zhao, J.; Huan, S. 2013. The effect of shrinkage anisotropy on tangential rheological properties of Asian White birch disks. Bioresources 8(4):5235-5243.

Hassani, M; Wittel, F.; Hering, S.; Herrmann, H. 2015. Rheological model for wood. Comput Methods Appl Mech Engrg 283:1032-1060.

Hunt, D.G.; Shelton, C.F. 1988. Longitudinal moisture-shrinkage coefficients of softwood at the mechano-sorptive creep limit. Wood Science and Technology 22:199-210.

Kang, W.; Lee, N.; Jung, H. 2004. Simple analytical methods to predict one - and two dimensional drying stresses and deformations in lumber. Wood Science and Technology 38:417-428. 181.

Keey, R.; Langrish, T.; Walker, J. 2000. Kiln-drying of lumber. Springer-Verlag, Berlin, pp. 65-

Langrish, T. A. G. 2013. Comparing continuous and cyclic drying schedules for processing hardwood timber: The importance of mechanosorptive strain. Drying Technology 31:1091-1098.

Lazarescu C.; Avramidis, S.; Oliveira, L. 2009. Modeling shrinkage response to tensile stresses in wood drying: I. Shrinkage moisture interaction in stress-free specimens. Drying Technology 27(11):1183-1191.

Mårtensson, A. 1994. Mechano-sorptive effects in wooden material. Wood Science and Technology 28:437-449.

Moutee, M.; Fafard, M.; Fortin, Y.; Laghdir, A. 2005. Modeling the creep of wood cantilever loaded at free end during drying. Wood Fiber and Science 37(3):521-534.

Moutee, M.; Fortin, Y.; Laghdir, A.; Fafard, M. 2010. Cantilever experimental setup for rheological parameter identification in relation to wood drying. Wood Science and Technology 44:3149 .

Pang, S. 2000. Modelling of stress development during drying and relief during steaming in Pinus radiata lumber. Drying Technology 18(8):1677-1696.

Pang, S. 2002. Investigation of effects of wood variability and rheological properties on lumber drying: application of mathematical models. Chemical Engineering Journal 86:103-110.

Salinas, C.; Chavez, C.; Ananías, R.; Elustondo, D. 2015. Unidimensional simulation of drying stress in radiata pine wood. Drying Technology 33(8): 996-1005.

Segovia, F.; Blanchet, P.; Laghdir, A.; Cloutier, A. 2013. Mechanical behavior of sugar maple in cantilever bending under constant and variable relative humidity conditions. International Wood Products Journal 4:225-231. 
Sepúlveda, V.; Pérez, N.; Salinas, C., Salvo, L.; Elustondo, D.; Ananías, R.A. 2015. Development of moisture and strain profiles during pre-drying of Eucalyptus nitens. Drying Technology 34(4): 428436. 